\title{
PREVALENCE OF DIABETES IN PATIENTS WITH FROZEN SHOULDER
}

\author{
Seema Maini', Aman Bansal2 ${ }^{2}$ Rajiv Arora ${ }^{3}$, Shiveta Bansal 4
}

1 Professor, Department of Physiology, Punjab Institute of Medical Sciences, Jalandhar, Punjab, India.

${ }^{2}$ Associate Professor, Department of Orthopaedics, Punjab Institute of Medical Sciences, Jalandhar, Punjab, India.

3 Professor and HOD, Department of Physiology, Punjab Institute of Medical Sciences, Jalandhar, Punjab, India.

${ }^{4}$ Associate Professor, Department of Physiology, Punjab Institute of Medical Sciences, Jalandhar, Punjab, India.

\section{ABSTRACT}

\section{BACKGROUND}

Diabetes mellitus is associated with serious complications. There is a strong correlation between diabetes mellitus and musculoskeletal disorders especially frozen shoulder. There are degenerative changes and abnormalities of collagen repair due to poor circulation.

\section{MATERIALS AND METHODS}

100 patients of frozen shoulder were selected. A detailed history regarding diabetes and shoulder symptoms was taken and every participant was subjected to investigations like fasting blood sugar along with post prandial blood sugar and HbA1c.

\section{RESULTS}

It was found that prevalence of diabetes mellitus among patients with frozen shoulder was $36 \%$. Poor diabetic control was seen in most of the diabetic patients with frozen shoulder.

\section{CONCLUSION}

The results of this study concluded that all the patients of frozen shoulder should be investigated for diabetes mellitus. And a good glycaemic control should also be ensured along with other modalities of treatment of frozen shoulder.

\section{KEY WORDS}

Diabetes Mellitus, Glycaemic Control, Frozen Shoulder

HOW TO CITE THIS ARTICLE: Maini S, Bansal A, Arora R, et al. Prevalence of diabetes in patients with frozen shoulder. J. Evolution Med. Dent. Sci. 2019;8(11):804-806, DOI: 10.14260/jemds/2019/177

\section{BACKGROUND}

Diabetes is an endocrine disorder, characterized by hyperglycaemia which leads to serious long-term complications. There is enough awareness about the micro and macrovascular complications like neuropathy, retinopathy, nephropathy and atherosclerotic complications of the disease. However musculoskeletal complications also contribute to loss of quality of life in these patients. Common musculoskeletal complications of diabetes include stiff hand syndrome, Dupuytren's contracture, various types of tendinitis, periarthritis of shoulder and frozen shoulder or adhesive capsulitis. ${ }^{1,2}$ Diabetic patients present with adhesive capsulitis at an early age. ${ }^{3}$

Pain, stiffness and restricted movements of the affected shoulder are the characteristic features of frozen shoulder. There is difficulty in sleeping due to pain in the affected shoulder. Frozen shoulder is more prevalent in diabetic patients as compared to non- diabetics. In diabetic patients, the prevalence of frozen shoulder is found to be $11-30 \%$ whereas in non- diabetics it is $2-10 \% .4,5,6$

There is abnormal collagen repair and degenerative changes due to poor circulation, which leads to higher incidence of frozen shoulder in diabetics. ${ }^{7}$

'Financial or Other Competing Interest': None.

Submission 16-02-2019, Peer Review 08-03-2019,

Acceptance 11-03-2019, Published 18-03-2019.

Corresponding Author:

Dr. Aman Bansal,

House No. 431, Chhoti Baradari, Part-I,

Jalandhar-144022, Punjab, India.

E-mail: dramanbansal@gmail.com

DOI: $10.14260 /$ jemds $/ 2019 / 177$

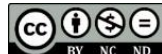

Hyper-glycaemia in diabetic patients leads to formation of advanced glycosylation end products (AGEs), which leads to cross linking of collagen, tendons and ligaments. As a result there is increase in stiffness of these structures and they are rendered weak. ${ }^{8}$ Diabetic patients have increased levels of intercellular adhesion molecule-1 in their shoulder capsule tissue which leads to inflammatory reaction followed by fibrosis. ${ }^{9}$ Increased rate of fibrosis also leads to development of disorders like Dupuytren's contracture in diabetic patients. ${ }^{10}$

Patients of frozen shoulder should be screened for diabetes as a routine so that along with other modalities of treatment like medications and physiotherapy, effective glycaemic control is ensured for a better prognosis and improved quality of life.

\section{Aim of The Study}

This study aims at finding the prevalence of diabetes in patients with frozen shoulder.

\section{MATERIALS AND METHODS}

This is a cross sectional study which included 100 subjects selected from the patients of frozen shoulder aged 35 years and above attending orthopaedics OPD of Punjab Institute of Medical Sciences, Jalandhar. Sample size was calculated based on prevalence found in similar study done by Tighe and Oaklay in 2008.11 In this study prevalence of diabetes was found to be $38.6 \%$ in patients with adhesive capsulitis of shoulder. Formula applied to calculate sample size was, 4 $\mathrm{pq} / \mathrm{E} 2$, where $\mathrm{E}$ is $10 \%$ and $\mathrm{q}$ is 1-p. (E stands for error and $\mathrm{p}$ stands for prevalence) Sample size calculated by applying this formula was 94.4 , so a total of 100 subjects were included in 
the present study. Frozen shoulder was diagnosed based on pain, stiffness and restricted motion in the affected shoulder. Diagnosis of frozen shoulder was confirmed by X-Ray of the affected shoulder. Patients with the H/O surgery, trauma, rheumatoid arthritis, paralysis, gout, myocardial infarction and thyroid disorder were not included in the study. A detailed history of shoulder symptoms and diabetes was taken from every subject. After physical examination and detailed examination of affected as well as other shoulder was done. Every subject was then investigated for fasting and post prandial blood sugar levels and HbA1c.

This study was approved by the institutional ethical committee of PIMS, Jalandhar and informed consent was taken from every subject. Data was analysed by using percentage analysis method.

\section{RESULTS}

There were 48 females (48\%) and 52 males (52\%) in the study group. Their mean age was 47.80 years. There were 18 patients $(18 \%)$ in the age group of 35 to 45 years, 49 patients $(49 \%)$ in the age group of 46 to 55 years, 30 patients (30\%) in the age group of 56 to 65 years and 3 patients (3\%) were above 65 years of age. There was a history of diabetes in $41 \%$ of the total participants in their immediate family (Siblings or parents or both).

\begin{tabular}{|c|c|}
\hline Gender & Number (Percentage) \\
\hline Male & $48(48 \%)$ \\
\hline Female & $52(52 \%)$ \\
\hline \multicolumn{2}{|c|}{ Table 1. Gender Wise Distribution of Study Subjects } \\
\hline
\end{tabular}

\begin{tabular}{|c|c|}
\hline Age Groups & Number (Percentage) \\
\hline 35-45 Yrs. & $18(18 \%)$ \\
\hline $46-55$ Yrs. & $49(49 \%)$ \\
\hline 56-65 Yrs. & $30(30 \%)$ \\
\hline 66 Yrs. and Above & $3(3 \%)$ \\
\hline \multicolumn{2}{|c|}{ Table 2. Age Wise Distribution of Study Subjects } \\
\hline
\end{tabular}

There were 36 patients (36\%) in the study group who were diabetic, with 23 patients (64\%) who were known diabetics and 13 patients (36\%) were not aware of their diabetic status. They were diagnosed with diabetes mellitus during present study as shown by their blood glucose levels and their HbA1c was also found to be in the diabetic range (6.5\% and above). 11 of the study participants (11\%) had their HbA1c levels in the pre diabetic range (Between 5.7 and $6.4 \%$ ) Out of diabetic patients 22 patients (61\%) showed poor diabetic control as depicted by their HbA1c levels (above 7\%), 14 patients (39\%) showed good diabetic control (HbA1c below 7\%).

\begin{tabular}{|c|c|}
\hline Diabetic Status & Number (Percentage) \\
\hline Diabetics (HbA1c > 6.5\%) & $36(36 \%)$ \\
\hline Pre-Diabetics (HbA1c 5.7-6.4\%) & $11(11 \%)$ \\
\hline Non-Diabetics (HbA1c < 5.7\%) & $53(53 \%)$ \\
\hline \multicolumn{2}{|c|}{ Table 3. Diabetic Status of the Study Subjects } \\
\hline
\end{tabular}

\begin{tabular}{|c|c|}
\hline Glycaemic Control & Number (Percentage) \\
\hline Poor Control (HbA1c $>7 \%)$ & $22(61 \%)$ \\
\hline Good Control (HbA1c $<7 \%)$ & $14(39 \%)$ \\
\hline Total & $\mathbf{3 6}(\mathbf{1 0 0} \%)$ \\
\hline Table 4. Glycaemic Control in Diabetic Subjects \\
\hline
\end{tabular}

\section{DISCUSSION}

This study showed that $36 \%$ patients of frozen shoulder visiting the orthopaedics OPD had diabetes mellitus. Out of them $23 \%$ were known diabetics and $13 \%$ had undiagnosed diabetes. $11 \%$ had their $\mathrm{HbA} 1 \mathrm{c}$ in the pre diabetic range i.e., between 5.7 and $6.4 \%$. Rest $53 \%$ patients of frozen shoulder were found to be euglycemic. $41 \%$ patients had history of diabetes mellitus in their immediate family.

A prevalence of diabetes was found to be $36 \%$ in the patients with frozen shoulder in the present study. Results of this study are consistent with other studies conducted when it comes to prevalence of diabetes in frozen shoulder patients. In a study conducted by Tighe and Oaklay in 2008, prevalence of diabetes was found to be $38.6 \%$ in the patients with adhesive capsulitis, also the $32.95 \%$ study participants were found to be pre-diabetics. ${ }^{11}$ According to another study prevalence of diabetes mellitus was found to be $30 \%$ in patients of adhesive capsulitis. ${ }^{12}$

Out of all the patients of FS with diabetes $61 \%$ showed poor diabetic control and 39\% showed good diabetic control as shown by their HbA1c levels. These findings are consistent with a study conducted by Justin et al which showed that patients with poorly controlled blood sugar levels over a long time interval have an increased possibility of developing adhesive capsulitis. ${ }^{13}$ In another study it was concluded that glycaemic control assessed by HbA1c is a very important factor affecting the development of musculoskeletal manifestations in type 2 diabetes mellitus. ${ }^{14}$

\section{CONCLUSION}

Patients of frozen shoulder should be investigated for diabetes mellitus as a routine. While treating the frozen shoulder through various modalities of treatment like medication, physiotherapy and surgical correction, a good glycemic control should also be ensured in the diabetic patients. Patients should also be educated about the role of management of blood sugar levels in the treatment of frozen shoulder.

\section{REFERENCES}

[1] Labeidz Odrobina D, Kay J. Rheumatic manifestations of diabetes mellitus. Rheum Dis Clin North Am 2010;36(4):681-99.

[2] Arkkila PE, Gautier JF. Musculoskeletal disorders in diabetes mellitus: an update. Best Pract Res Clin Rheumatol 2003;17(6):945-70.

[3] Smith LL, Burnet SP, McNeil JD. Musculoskeletal manifestations of diabetes mellitus. Br J Sports Med 2003;37(1):30-5.

[4] Bridgman JF. Periarthritis of shoulder and diabetes mellitus. Ann Rheum Dis 1972;31(1):69-71.

[5] Laquesne M, Dang N, Bensasson $M$, et al. Increased association of diabetes mellitus with capsulitis of shoulder and shoulder-hand syndrome. Scand J Rheumatol 1977;6(1):53-6.

[6] Balci N, Balci MK, Tuzuner S. Shoulder adhesive capsulitis and shoulder range of motion in type 2 diabetes mellitus: association with diabetic complications. J Diabetic Complications 1999;13(3):135-40.

[7] Grisanti R. Frozen shoulder: the diabetic connection. American Chiropractic Magazine, Volume 32, Issue 5. 
[8] Goldin A, Beckman JA, Schmidt AM, et al. Advanced glycosylation end products: sparkling the development of vascular injury. Circulation 2006;114(6):597-605.

[9] Kim YS, Kim JM, Lee YG, et al. Intercellular adhesion molecule-1 (ICAM-1, CD54) is increased in adhesive capsulitis. J Bone Joint Surg Am 2013;95(4):e181-e8.

[10] Siegel LB, Cohen NJ, Gall EP. Adhesive capsulitis: a sticky tissue. Am Fam Physician 1999;59(7):1843-52.

[11] Tighe CB, Oakley WS Jr. The prevalence of a diabetic condition and adhesive capsulitis of the shoulder. South Med J 2008;101(6)591-5.
[12] Zreik NH, Malik RA, Charalambous CP. Adhesive capsulitis of the shoulder and diabetes: a metaanalysis of prevalence. Muscles Ligaments Tendons J 2016;6(1):26-34.

[13] Chan JH, Ho BS, Alvi HM, et al. The relationship between the incidence of adhesive capsulitis and haemoglobin A1c. J Shoulder Elbow Surg 2017;26(10):1834-7.

[14] Youssef AA, Shabana AA, Senna MK, et al. Study of musculoskeletal disorders in a cohort of Egyptian diabetic patients and its relation to glycemic control. Tanta Med J 2016;44(4):151-6. 